DOI https://doi.org/10.30525/978-9934-26-073-5-1-51

\title{
THE PECULIARITIES OF FUNCTIONING OF THE VERBAL-VISUAL PUNS IN SOCIAL MEDIA
}

\author{
Dyrda I. A. \\ Doctor of Philosophy, \\ Senior Lecturer at the Department of English philology \\ Kryvyi Rih State Pedagogical University \\ Kryvyi Rih, Dnipropetrovsk region, Ukraine
}

The stylistic technique of pun has been under consideration by a lot of both national and foreign researchers of linguistics. But much in terms of the mechanisms of its functions and its formation still remains ambiguous. Firstly, there is no commonly accented definition among researchers in pointing out the essence of the stylistic device in question. Differences in the understanding of pun and its distinction from other stylistic devices, mechanisms of its implementation justify the necessity of its further investigation.

In foreign scientific linguistic works, the notion «pun» is often interpreted in the context of humor. According to the American online dictionary Merriam-Webster the notion of «pun» is as well interpreted in the context of humour: «the usually humorous use of a word in such a way as to suggest two or more of its meanings or the meaning of another word similar in sound» [5]. As for Cambridge Dictionary there is the following understanding of «pun»: «a humorous use of a word or phrase that has several meanings or that sounds like another word» [3]. Macmillan Dictionary also defines the phenomenon of «pun» considering the aspect of humour: «a humorous use of a word that has two meanings, or of words with the same sound but different meanings» [4].

In the work «The Funny Thing About Incongruity: A Computational Model of Humor in Puns» Kao J. T, Levy R., Goodman, N. D. emphasize that one sentence must evoke two different interpretations in order to become a pun that agrees with the concept of inconsistency as a prop of humor. They develop their model on homophone puns that is puns that contain words that sound identical to other words in English, because the space for possible interpretations of homophone puns is relatively limited and clearly defined [2].

According to scientist E. Shmelyova pun is understood as a stylistic device based on a linguo-creative play on the meanings of a word or word in a phrase as a result of simultaneous or sequential bisociative realization of several meanings of the unit. Thus, she defines pun as a stylistic device which is associated with certain effects. They imply the following ones: the comic 
effect, the effect of deceived expectations, the effect of cognitive dissonance and the effect of double or triple meanings [6].

Therefore due to the complexity of interpretation of the concept of «pun» there is still no common understanding of the concept of this phenomenon. Most philologists consider «pun» in terms of a humorous aspect, and also identify the concepts of «pun» and «word play».

It is necessary to stick to a broad interpretation of the notion in question. And pun should be considered as a method of creating a humorous effect, the stylistic effect of which is based on the contrast of form and meaning of words that are realized in context. While word play is supposed to be understood as a generic term with a broader meaning.

On analyzing the theoretical aspects of pun analysis, different approaches to the concept, classification and typology of pun, it is appropriate to stick to the classification of the Jordanian scientist Yousef Bader. According to his classification there are 6 types of puns identified: homophonic, homographic or heteronymic, homonymous, compund, recursive and visual ones. He is the one who focused his attention on the visual pun [1].

Both national and foreign scientists in their studies of English-language media headlines mainly take into consideration such well known publications as The New York Times, The Guardian, The Sun etc. Though pun as a stylistic device within social networks has not been thoroughly analyzed. For instance, an online platform Instagram has not been widely taken into consideration for studying puns. According to the Statista Global Business Data Platform Instagram plays a leading role among social networking platforms consequently it should be taken into account.

Via the methods of framing analysis the Instagram posts The New Yorker (@ newyorkercartoon) have been analyzed. The focus has been on the verbally-visual puns.

On considering the post (from December, 16, 2020) it demonstrates us a caterpillar addressing the one who is eating. The first frame (F1) «Are you sure you're hungry? Or are you maybe just eating because you're bored?» This verbal part is traditionally interpreted the one said in terms of healthy eating and believing that people often tend to eat not in order to satisfy their need but just for the sake of killing time when they are bored. The second frame (F2) is a visual one with caterpillars whose just satisfy their surviving instincts. 


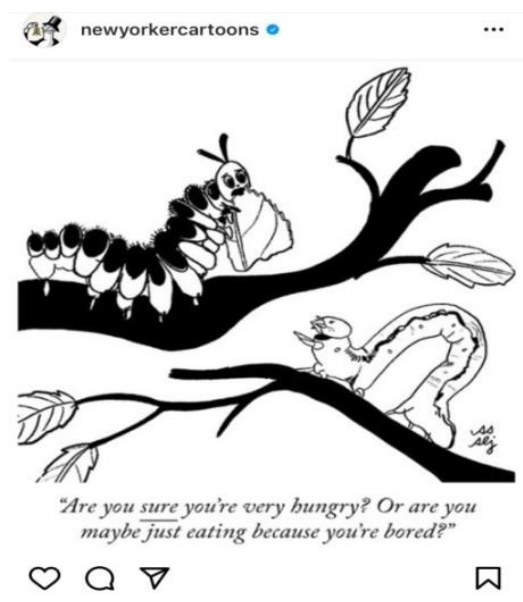

Pic. 1.1 A cartoon by @sophielucidojohnson and @ skullmoski

The post (March, 9, 2021) has been analyzed. The first frame (F1) demonstrates a verbal aspect about greeting and treats. The second one is a visual one which shows a lady sitting in front of her computer thus it implies the situation during the quarantine. In this case the meaning can be understood only if the visual and verbal aspects are interpreted inseparably.

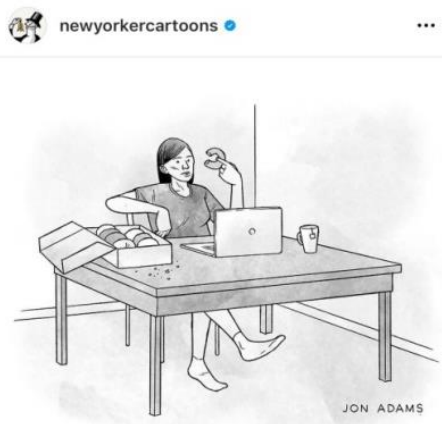

"Good morning, everyone. I brought doughnuts."

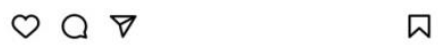

Pic. 1.2 A Doughnut Day at the Office by @ cityclops

As for the post (April, 15, 2021) the first cognition (F1) is marked as coming out of shells again which is not quite a good thing for turtles but it 198 
transforms into the second frame $(\mathrm{F} 2)$ when recipients understand it as the one which implies that people will be free to get back to their ordinary lives after quarantine restrictions.

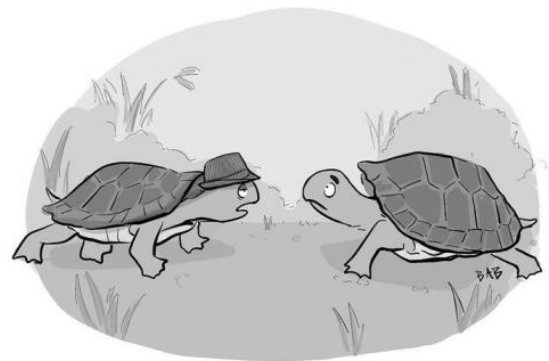

"I panicked when they said we could come out of our shells again."
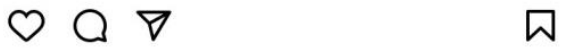

Pic.1.3 A cartoon by @b_a_bourgeois

Thus most of the puns presented in Instagram posts are verbal-visual but there are as well purely visual ones. But from a linguistic point of view it is more appropriate to analyze verbal-visual ones.

\section{References:}

1. Bader Y. A linguistic and cultural analysis of pun expressions in journalistic articles in Jordan. European Scientific Journal. 2014. Vol.2. P. 18-29

2. Kao J. T, Levy R., Goodman N. D. The Funny Thing About Incongruity. A Computational Model of Humor in Puns. Proceedings of the Annual Meeting of the Cognitive Science Society. 2013. Vol. 35. P. 728-733. Retrieved from https://escholarship.org/uc/item/04j190sw

3. Online Cambridge English Dictionary: http://dictionary.cambridge.org

4. Online Macmillan Dictionary: https://www.macmillandictionary.com/

5. Online Merriam-Webster Online English Dictionary: http://merriamwebster.com 
6. Shmeleva E. S. Models of puns. Bulletin of Moscow state linguistic university. 2017. Vol. 10 (783). P. 77-87

7. Statista. Most popular social networks worldwide as of October 2020, ranked by number of active users. Retrieved from https://www.statista.com/ statistics/272014/global-social-networks-ranked-by-number-of-users/

DOI https://doi.org/10.30525/978-9934-26-073-5-1-52

\title{
VERBAL REALISATION OF HUMOR AND ITS FEATURES IN THE GERMAN-SPEAKING STAND-UP COMEDY GENRE
}

\author{
Zhuhai V. V. \\ First year postgraduate student \\ Institute of Philology \\ Taras Shevchenko National University of Kyiv \\ Kyiv, Ukraine
}

The following research aims to debunk some of the existing myths about the lack of humour in the German-speaking cultural space using the material of the German-speaking comedy in the sphere of stand-up while also developing a theoretical basis for the humor's analysis with the help of contextual, linguistic, and pragmatic analysis.

The phenomena of humor and laughter have puzzled representatives of philosophical, psychological, and linguistic thought for centuries, starting with Plato, followed up with the early Christians and great thinkers, like R. Descartes, I. Kant, A. Schopenhauer, psychologists like Freud, even the author of the evolution theory, C. Darwin. [6, p. 4-8] Laughter has been thought to be a hostility reflex by some [6, p. 4] and called the ultimate relief instrument by others $[6, \mathrm{p} .5]$, while the more modern scholars would call it a result of one's expectations being violated $[6$, p. 8]. Throughout our research, we established that there is some confusion regarding what humor and laughter are. According to some sources [5, p. 2], laughter is the luxury reflex, summoning the coordination motion of 15 facial nerves, however serving no obvious biological purpose other than stress relief.

As a comedic genre, stand-up comedy has existed for at least a hundred fifty plus years, thought to have originated in the 1840s in Great Britain. [1] However, stand-up comedy in its modern variation started to take form a couple of decades later with Mark Twain's humoristic performances in the United States [1]. The genre evolved relatively slowly until the introduction of 